\title{
Effects of candesartan and amlodipine on cardiovascular events in hypertensive patients with chronic kidney disease: subanalysis of the CASE-J Study
}

\author{
Takao Saruta ${ }^{1}$, Koichi Hayashi ${ }^{1}$, Toshio Ogihara ${ }^{2}$, Kazuwa Nakao ${ }^{3}$, Tsuguya Fukui ${ }^{4}$ and Kohshiro Fukiyama ${ }^{5}$, \\ for the CASE-J Study Group
}

We examined the effects of candesartan and amlodipine on cardiovascular events in hypertensive patients with chronic kidney disease (CKD) using the data from the Candesartan Antihypertensive Survival Evaluation in Japan (CASE-J) trial. CKD was defined as proteinuria and/or decreased GFR $\left(<60 \mathrm{ml}\right.$ per min per $\left.1.73 \mathrm{~m}^{2}\right)$ at enrollment. Among 2720 subjects with CKD, there were 1376 and 1344 patients in the candesartan and the amlodipine group, respectively. During a 3.2-year follow-up, cardiovascular event rate did not differ in the two groups ( $7.2 \%$ for candesartan and $7.6 \%$ for amlodipine). In the subgroup analysis based on the CKD stage, there were no significant differences in the incidence rates of cardiovascular events between the two groups in stages $1+2$ and 3 CKD. In stage 4 CKD, however, candesartan reduced the incidence of cardiovascular events ( $55 \%$ risk reduction), particularly of renal events ( $81 \%$ risk reduction), compared with amlodipine. Furthermore, composite cardiovascular events were increased as the CKD stage progressed, and this effect was exaggerated in the presence of proteinuria. Finally, the new onset of diabetes was less in the candesartan-based regimen in stage $3 \mathrm{CKD}$. In conclusion, candesartan protected hypertensive patients with CKD more potently against renal events, particularly in moderately-to-severely impaired CKD. Furthermore, candesartan prevented a new onset of diabetes in CKD, which would be favorable for the long-term management of CKD.

Hypertension Research (2009) 32, 505-512; doi:10.1038/hr.2009.44; published online 24 April 2009

Keywords: cardiovascular events; CKD; diabetes

\section{INTRODUCTION}

A growing body of evidence has been accumulated suggesting that proteinuria and a decreased glomerular filtration rate (GFR) constitute critical risk factors not only for the loss of renal function but also for increased cardiovascular morbidity and mortality, independent of the established risk factors. ${ }^{1-7}$ Indeed, the event rates of cardiovascular disease during the progression of chronic kidney disease (CKD) are higher than those observed at the end stage of CKD, which suggests a substantial contribution of early-stage CKD to death in patients with $\mathrm{CKD}{ }^{8}$ In addition to the recognition of $\mathrm{CKD}$ as a serious risk factor for cardiovascular events, CKD has been highlighted because of its enormous burden on medical expenditure. Although clinical practice guidelines on $\mathrm{CKD}$ have been published worldwide to mitigate the progression of $\mathrm{CKD}$ and the subsequent development of cardiovascular events, ${ }^{9,10}$ the number of patients requiring dialysis therapy is still growing, reaching approximately 260000 patients in our country. ${ }^{11}$

Hypertension contributes substantially to cardiovascular morbidity and mortality, which is also recognized as a precipitating and aggravating factor for CKD. It is established that the renin-angiotensin system (RAS) plays a pivotal role in the pathogenesis of hypertension, CKD and cardiovascular events. ${ }^{12}$ Furthermore, several lines of clinical trials have demonstrated that the inhibition of RAS by the angiotensin receptor blocker (ARB) confers protective action on cardiovascular organs as the first-line treatment strategy in diabetic $^{13,14}$ as well as non-diabetic ${ }^{15}$ hypertensive patients with CKD. In contrast, a therapeutic role of the calcium channel blocker (CCB) in the progression of $\mathrm{CKD}$ in hypertensive patients remains a matter of controversy, with some studies showing benefit, ${ }^{16,17}$ whereas other trials show no benefit ${ }^{13,18}$ by the CCB. As the ethnical difference

${ }^{1}$ Department of Internal Medicine, Keio University School of Medicine, Tokyo, Japan; ${ }^{2}$ Osaka General Medical Center, Osaka, Japan; ${ }^{3}$ Department of Medicine and Clinical Science, Kyoto University Graduate School of Medicine, Kyoto, Japan; ${ }^{4}$ St Luke's International Hospital, Tokyo, Japan and 5Japan Seaman's Relief Association Moji Hospital, Fukuoka, Japan

Correspondence: Dr K Hayashi, Department of Internal Medicine, School of Medicine, Keio University, 35 Shinanomachi, Shinjuku-ku, Tokyo 160-8582, Japan. E-mail: khayashi@sc.itc.keio.ac.jp

Received 4 December 2008; revised 5 March 2009; accepted 12 March 2009; published online 24 April 2009 
between Japanese and Western populations as well as divergent lifestyle (for example, salt intake) and incidence rate of cerebrovascular events affect the outcome when the effects of antihypertensive therapy are compared, appropriate evaluation is required to elucidate the efficacies of ARB and CCB for reducing the cardiovascular events in patients with CKD.

In the large-scale Candesartan Antihypertensive Survival Evaluation in Japan (CASE-J) Trial, the ability of an ARB candesartan cilexetil and a CCB amlodipine besylate to reduce the cardiovascular events in high-risk hypertensive patients was assessed. ${ }^{19,20}$ This trial revealed that the two drugs equally suppressed the incidence of cardiovascular events during the 3.2-year follow-up period. In the current subanalysis, we evaluated the effects of candesartan and amlodipine on the incidence of cardiovascular events in hypertensive patients with CKD. Furthermore, the effect of CKD on the incidence of new-onset diabetes was assessed.

\section{METHODS}

\section{Study design and population}

The rationale and complete design of the CASE-J Trial have been reported earlier. ${ }^{19}$ Briefly, the CASE-J Study was a prospective, multicenter, randomized, open-label, active-controlled, two-arm parallel-group comparison in Japan with a response-dependent dose titration and blinded assessment of the end point. This trial was a comparative study of the effects of candesartan cilexetil and amlodipine besylate in high-risk hypertensive patients as defined by the Hypertension Treatment Guideline of the Japanese Society of Hypertension; ${ }^{21}$ (1) systolic $\mathrm{BP} \geqslant 180 \mathrm{~mm} \mathrm{Hg}$ or diastolic $\mathrm{BP} \geqslant 110 \mathrm{~mm} \mathrm{Hg}$, (2) type II diabetes, (3) a history of stroke or transient ischemic attack, (4) left-ventricular hypertrophy, angina pectoris or a history of myocardial infarction, (5) proteinuria or a serum creatinine $\geqslant 1.3 \mathrm{mg} \mathrm{dl}^{-1}$ or (6) arteriosclerotic peripheral artery obstruction. The exclusion criteria have been reported earlier. ${ }^{19}$ The Ethics Committee at Kyoto University Graduate School of Medicine approved the CASE-J Trial protocol according to the principles of the Helsinki Declaration. After obtaining informed consent, the patients were randomly assigned to the trial arms. The targets for the control of blood pressure (BP) were $<130$ / $85 \mathrm{~mm} \mathrm{Hg}$ for ages $<60$ years, $140 / 90 \mathrm{~mm} \mathrm{Hg}$ for ages $60-69$ years, 150/ $90 \mathrm{~mm} \mathrm{Hg}$ for ages $70-79$ years and $160 / 90 \mathrm{~mm} \mathrm{Hg}$ for ages $\geqslant 80$ years.

For the study agents, $4-8 \mathrm{mg}$ per day candesartan was orally administered to the patients in the candesartan group. When the patient's BP did not reach the target BP, the dose was increased to a maximal dose of $12 \mathrm{mg}$ per day. For the amlodipine group, $2.5-5 \mathrm{mg}$ per day amlodipine was given orally. For the same reason as candesartan, the dose was also increased to $10 \mathrm{mg}$ per day. The primary end point was a composite of the first incidence of sudden death, stroke/transient cerebral ischemic attack, acute myocardial infarction/cardiac failure/angina, doubling of the serum creatinine level, a serum creatinine level $\geqslant 4.0 \mathrm{mg}$ per $100 \mathrm{ml}$, end-stage renal disease, or dissecting aortic aneurysm/ arteriosclerotic occlusion of a peripheral artery, as indicated in our earlier publication. ${ }^{19}$ A new onset of diabetes (fasting glucose $\geqslant 126 \mathrm{mg}$ per $100 \mathrm{ml}$, randomly sampled blood glucose $\geqslant 200 \mathrm{mg}$ per $100 \mathrm{ml}$ or $\mathrm{HbAlc} \geqslant 6.5 \%$ ) was also evaluated as a prespecified end point. The event evaluation was performed independently by the event evaluation committee using the PROBE method. The study period was for 3 years or longer.

For the renal subanalysis, 4728 patients were enrolled and randomly assigned to the candesartan or amlodipine group (2364 patients in each group). On the basis of CKD Guidelines of the Japanese Society of Nephrology, ${ }^{9}$ patients at enrollment with positive urinary protein tests by dipstick analysis or an eGFR of $<60 \mathrm{ml}$ per min per $1.73 \mathrm{~m}^{2}$ by a predictive equation $\left(\mathrm{eGFR}=0.741 \times 175 \times \mathrm{Age}^{-0.203} \times \mathrm{Cr}^{-1.154}(\times 0.741\right.$, if female $)$; $\mathrm{Cr}$, serum creatinine) were defined as having CKD in this study. The two agents were then compared for the incidence rates of cardiovascular events in these patients. We also carried out stratified analyses according to the CKD stage. ${ }^{9,10}$

\section{Statistical analyses}

Data are expressed as mean \pm s.d. or proportions. We compared continuous variables using the student's $t$-test. Frequency analysis was carried out by $\chi^{2}$ test.
Only the time to the first cardiovascular event was considered for the composite primary end point. Similarly, only the first event in each category was counted for the other end points (sudden death, cerebrovascular events, cardiac events or renal events). The incidence proportions were calculated by the Kaplan-Meier method, and were compared using the log-rank test. The hazard ratio (HR) and 95\% confidence intervals (CIs) for cardiovascular events were estimated using Cox regression analysis and compared by Wald test. For comparing the HR for cardiovascular events in each CKD stage with that of the non-CKD stage, we used multiple Cox regression analysis adjusted for treatment group, sex, age, body mass index, severe hypertension, type II diabetes, a history of cerebrovascular disease, cardiac disease and vascular disease. The analyses were carried out based on the intention-to-treat principle. The statistical tests were two-sided, and the significance level was set at 5\%. All statistical analyses were performed using statistical analysis system (SAS) version 9.1 (SAS Institute, Cary, NC, USA). This trial has been registered at the United States National Library of Medicine (www.clinicaltrials.gov; \# NCT00125463).

\section{RESULTS}

\section{Patient characteristics}

Among the hypertensive patients in the CASE-J Trial, 1376 and 1344 patients in the candesartan and amlodipine groups were shown to have CKD. The mean ages of these patients were 65.6 and 65.3 years, and the BP at enrollment was $163.3 / 91.8$ and $163.4 / 91.6 \mathrm{~mm} \mathrm{Hg}$, respectively (Table 1). Although a larger percentage of men was noted in the amlodipine group, no significant difference in BMI or underlying cardiovascular risk factors (Table 2) was observed between

Table 1 Patient characteristics in subjects with chronic kidney disease

\begin{tabular}{|l|c|c|c|}
\hline & Candesartan & Amlodipine & P value \\
\hline Total number & 1376 & 1344 & \\
\hline Males $(\%)$ & $684(49.7 \%)$ & $724(53.9 \%)$ & 0.030 \\
\hline Age $(\mathrm{y} / \mathrm{o})$ & $65.6 \pm 10.3$ & $65.3 \pm 10.6$ & 0.577 \\
\hline BMl $\left(\mathrm{kg} / \mathrm{m}^{2}\right)$ & $24.6 \pm 3.8$ & $24.5 \pm 3.6$ & 0.245 \\
\hline SBP $(\mathrm{mmHg})$ & $163.3 \pm 13.9$ & $163.4 \pm 13.9$ & 0.752 \\
\hline DBP $(\mathrm{mmHg})$ & $91.8 \pm 10.8$ & $91.6 \pm 11.5$ & 0.613 \\
\hline
\end{tabular}

Abbreviations: BMI, body mass index; SBP, systolic blood pressure; DBP, diastolic blood pressure. Results are mean \pm s.d.

\section{Table 2 Underlying cardiovascular risk factors}

\begin{tabular}{|c|c|c|c|c|}
\hline & & $\begin{array}{c}\text { Candesartan } \\
(n=1376)\end{array}$ & $\begin{array}{c}\text { Amlodipine } \\
(n=1344)\end{array}$ & $P$ value \\
\hline \multicolumn{2}{|c|}{ Severe HBP $\geq 180$ and/or $110 \mathrm{mmHg}$} & $256(18.6 \%)$ & $258(19.2 \%)$ & 0.694 \\
\hline Type 2 diabetes & & $585(42.5)$ & $569(42.3 \%)$ & 0.925 \\
\hline \multirow{3}{*}{$\begin{array}{c}\text { Cerebrovascular } \\
\text { disease }\end{array}$} & Cerebral hemorrhage & $28(2.0 \%)$ & $32(2.4 \%)$ & 0.539 \\
\hline & Cerebral infarction & $118(8.6 \%)$ & $103(7.7 \%)$ & 0.384 \\
\hline & TIA & $23(1.7 \%)$ & $15(1.1 \%)$ & 0.217 \\
\hline \multirow{3}{*}{ Cardiac disease } & LVH & $424(30.8 \%)$ & $435(32.4 \%)$ & 0.384 \\
\hline & Angina pectoris & $101(7.3 \%)$ & $90(6.7 \%)$ & 0.511 \\
\hline & Acute myocardial infarction & $65(4.7 \%)$ & $65(4.8 \%)$ & 0.891 \\
\hline Vascular disease & ASO & $21(1.5 \%)$ & $12(0.9 \%)$ & 0.132 \\
\hline
\end{tabular}

Abbreviations: ASO, arteriosclerosis obliterans; HBP, high blood pressure; LVH, left ventricular hypertrophy; TIA, transient ischemic attack. Data includes duplications. 
the two groups. Among the candesartan-treated and the amlodipinetreated groups, $57.1 \%$ and $44.3 \%$ of the patients in the respective groups received other antihypertensive drugs, including diuretics (26.2\% vs. $15.1 \%, P<0.001)$, $\beta$-blockers (24.1 vs. $18.1 \%, P<0.001)$, $\alpha$-blockers $(27.1$ vs. $17.2 \%, P<0.001)$ and $\alpha \beta$-blockers $(8.1$ vs. $5.7 \%$, $P=0.012)$.

\section{BP-lowering effects}

As shown in Figure 1, the mean BP was reduced from 163.3/ $91.8 \mathrm{~mm} \mathrm{Hg}$ at baseline to $136.3 / 77.0 \mathrm{~mm} \mathrm{Hg}$ after a 3-year trial period in the candesartan-based regimen and from 163.4/91.6 to 135.1/ $76.6 \mathrm{~mm} \mathrm{Hg}$ in the amlodipine-based regimen. After 3 years, systolic, but not diastolic, BP in the candesartan group was significantly, albeit slightly, higher than that in the amlodipine group (systolic BP, $1.2 \mathrm{~mm} \mathrm{Hg}, P=0.022$; diastolic BP, $0.4 \mathrm{~mm} \mathrm{Hg}, P=0.282$ ).

\section{Cardiovascular event rate}

Cardiovascular events-the primary end point-occurred in 99 $(7.2 \%)$ patients in the candesartan group (that is, $22.6 / 1000$ patientyears) and in $102(7.6 \%)$ patients in the amlodipine group (that is, 23.9/1000 patient-years); there were no differences between the two treatment groups (HR: 0.95 ; 95\% CI: $0.72-1.25 ; P=0.698$, Figure 2).

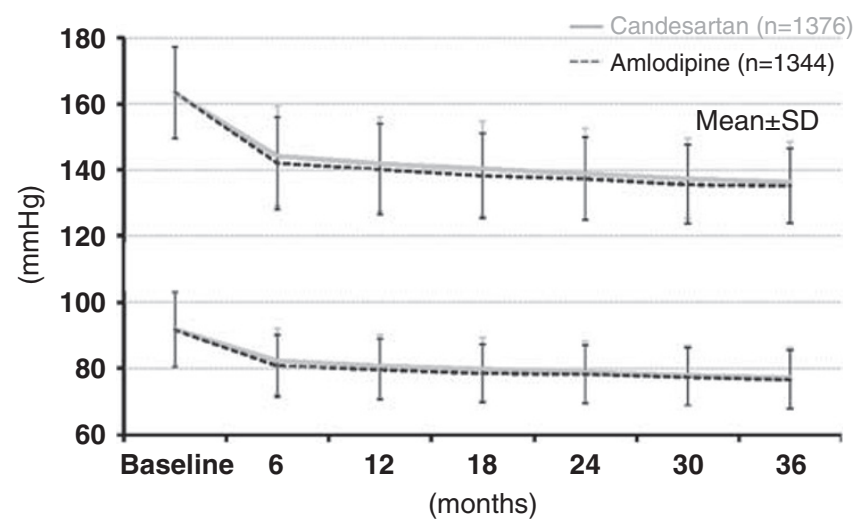

Candesartan : $163.3 / 91.8 \mathrm{mmHg}$ (baseline) $\rightarrow$ 136.3 / 77.0mmHg (3years) Amlodipine : $163.4 / 91.6 \mathrm{mmHg}$ (baseline) $\rightarrow 135.1 / 76.6 \mathrm{mmHg}$ (3years)

Figure 1 Changes in the blood pressure (BP) of patients with chronic kidney disease (CKD). Results are mean \pm s.d.

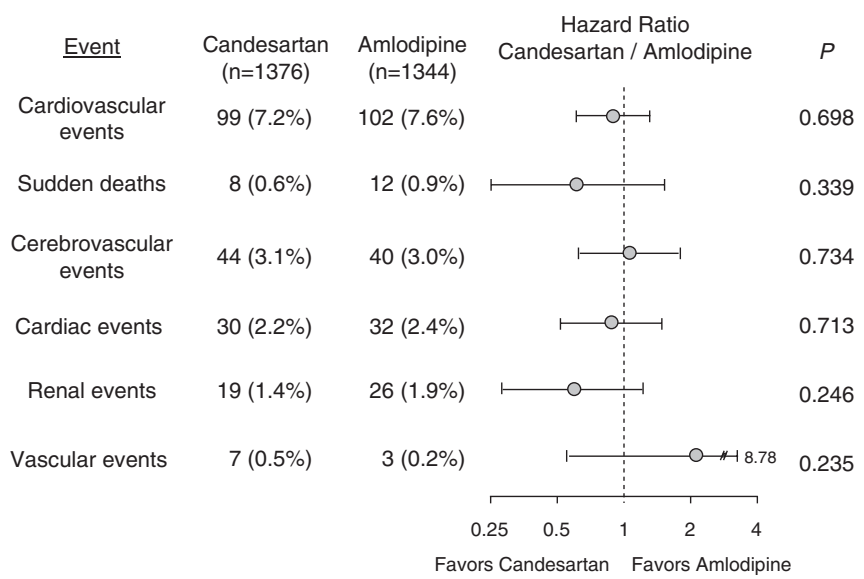

Figure 2 Comparison of the composite cardiovascular end point and each cardiovascular event. The first event for each category was counted.
On evaluating each event category, including sudden death, cerebrovascular events, cardiac events, renal events and vascular events, no differences were noted between the candesartan group and the amlodipine group.

\section{Stratified analyses}

Next, the event rates were evaluated according to the CKD stage. There was no significant difference between the two groups in the incidence rates of cardiovascular events for patients with stage $1+2(P=0.550)$ or stage 3 CKD $(P=0.972$, Figure 3$)$. In contrast, in patients with stage 4 $\mathrm{CKD}$ in which renal function was severely compromised, the candesartan treatment conferred significantly greater benefit than the amlodipine group in preventing cardiovascular events, exhibiting a $55 \%$ risk-reduction rate when compared with the amlodipine group (HR: 0.45; 95\% CI: $0.20-0.995 ; P=0.043$ ). Furthermore, when each event category was evaluated on the basis of CKD stage classification, no differences were noted between the two groups for cerebrovascular or cardiac events (Table 3 ). In stage $1+2$ or stage $3 \mathrm{CKD}$, the renal events did not favor any of the two treatment regimens. In stage 4 , the number of patients was less than those in other stages of CKD. Nevertheless, the candesartan-based regimen offered significantly lower renal events in stage $4 \mathrm{CKD}$, with $81 \%$ relative risk reduction observed when compared with amlodipine-based regimens. The percentage of the patients with stage $4 \mathrm{CKD}$ who received other antihypertensive agents was the same in the candesartan-treated and amlodipine-treated groups (diuretics, 31.3 vs. 33.1\%; $\beta$-blockers, 26.6 vs. $21.3 \%$; $\alpha$-blockers, 28.1 vs. $29.5 \%$; $\alpha \beta$-blockers, 6.3 vs. $6.6 \%$ ).

Figure 4 illustrates the Kaplan-Meier curves for renal events during the treatment with candesartan or amlodipine. Total incidence rates of renal events were moderately less in the candesartan-based regimen than in the amlodipine-based regimen $(P=0.243)$. In the stage $1+2$ and stage $3 \mathrm{CKD}$, the incidence rates of renal events were small, and there were no differences between the two groups. In contrast, the candesartan-based regimen preserved greater renal survival than the amlodipine-based regimen in patients with stage 4 CKD $(P=0.003)$; the event rate was markedly suppressed throughout the study period. We further evaluated the incidence of renal events in patients with or without proteinuria at entry in each stage of CKD. The patients with no proteinuria manifested very small incidence of renal events, and no difference was noted between candesartan-based and amlodipinebased regimens (Figure 5, left). In patients with proteinuria, the amlodipine-based regimen exhibited a marked elevation in renal events in stage $4 \mathrm{CKD}$, whereas the candesartan-based regimen showed only moderate increases in event rates in all stages of CKD (Figure 5, right).

\section{Effect of CKD and proteinuria on cardiovascular events}

The effect of CKD and proteinuria on the development of cardiovascular accidents was assessed in all patients with CKD and also assessed based on the CKD stage classification. The incidence of cardiovascular events in stage $1+2$ and stage 3 CKD was higher than that in the nonCKD group $(P<0.001$, Figure $6 a)$. The stage 4 group manifested markedly higher rates for cardiovascular events throughout the study period $(P<0.001)$. The relative HR in stage $1+2$, stage 3 and stage 4 was 3.05 (95\% CI: 1.99-4.67), 1.78 (95\% CI: 1.32-2.39) and 5.32 (3.33-8.50), respectively, compared with the non-CKD group. When each cardiovascular event category was evaluated, cerebrovascular and renal event rates were found elevated at early stages of CKD (that is, stage $1+2 ; P<0.001$ and $P=0.002$ for cerebrovascular and renal events, respectively). In contrast, cardiac accidents tended to increase at stage $3(P=0.070$, Figure $6 \mathrm{~b})$. 

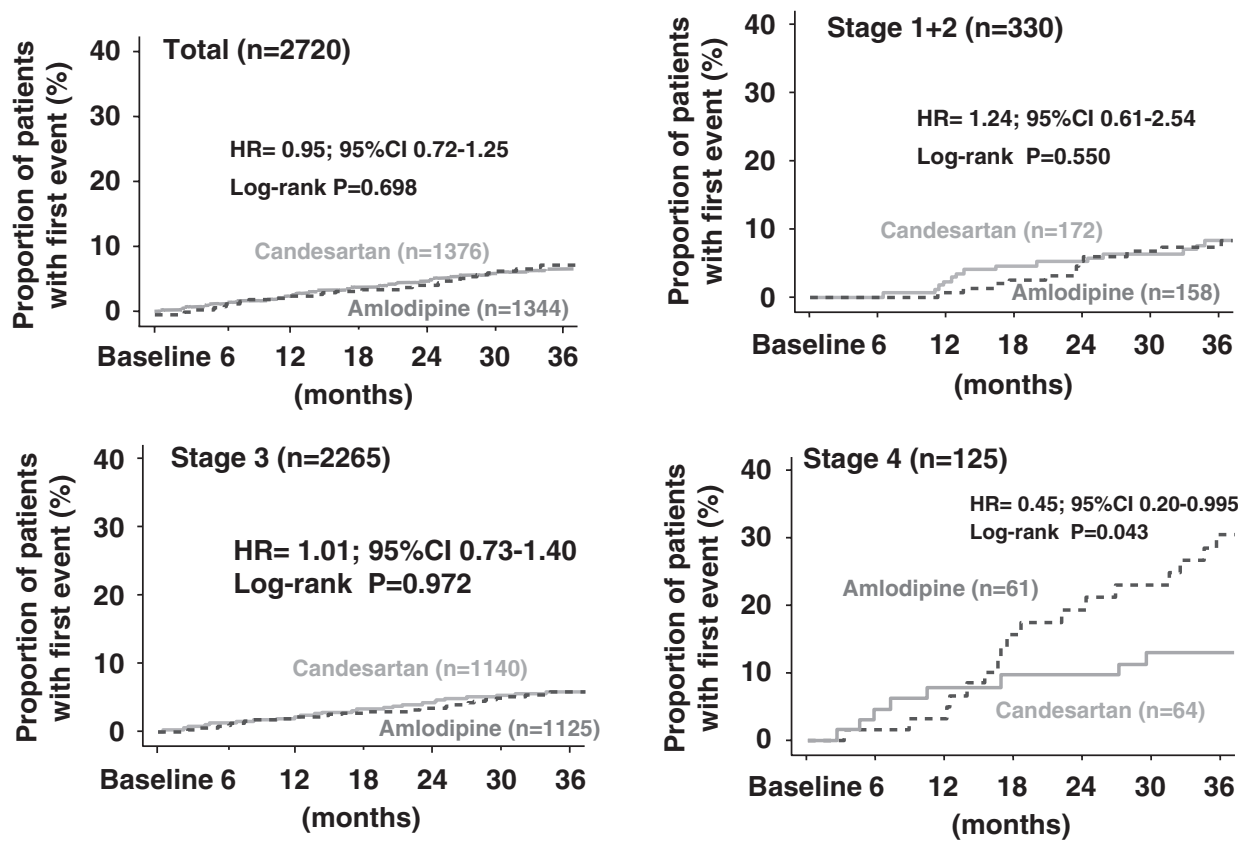

Figure 3 Kaplan-Meier curves of candesartan-based and amlodipine-based regimens for composite cardiovascular end point in various CKD stages.

Table 3 Comparison of composite cardiovascular end point and each cardiovascular event in various chronic kidney disease stages

\begin{tabular}{|c|c|c|c|c|}
\hline Cardiovascular events & $18(10.5)$ & $13(8.2)$ & $1.243(0.609-2.537)$ & 0.551 \\
\hline Cerebrovascular events & $11(6.4)$ & $7(4.4)$ & $1.402(0.544-3.618)$ & 0.484 \\
\hline Renal events & $2(1.2)$ & $3(1.9)$ & $0.604(0.101-3.616)$ & 0.581 \\
\hline Stage 3 & Candesartan $(n=1140)$ & Amlodipine $(n=1125)$ & $H R(95 \% \mathrm{Cl})$ & $P$ \\
\hline Cardiac events & $26(2.3)$ & $27(2.4)$ & $0.946(0.552-2.622)$ & 0.841 \\
\hline Renal events & $14(1.2)$ & $9(0.8)$ & $1.532(0.663-3.540)$ & 0.318 \\
\hline Stage 3 & Candesartan $(n=64)$ & Amlodipine $(\mathrm{n}=61)$ & $H R(95 \% \mathrm{Cl})$ & $P$ \\
\hline Cardiovascular events & $9(14.1)$ & $18(29.5)$ & $0.446(0.200-0.995)$ & 0.048 \\
\hline
\end{tabular}

Whether proteinuria altered the risk of cardiovascular events was assessed in all patients enrolled in the CASE-J Study. The presence of proteinuria was associated with greater incidence of cardiovascular events with a HR of 2.78 (2.16-3.58, $P<0.001$; Figure $6 \mathrm{c})$. When evaluated in each CKD stage, proteinuria exaggerated the risk of cardiovascular events in the stage 3 CKD $(P<0.001$, Figure $6 \mathrm{~d})$ and tended to increase in the stage $4 \mathrm{CKD}(P=0.093$, Figure 6e).

\section{New onset of diabetes}

During the 3.2-year observation period, the incidence of new onset of diabetes in stage $1+2(11.9 / 1000$ person-years $)$ or stage 3 (10.8/1000 person-years) did not differ from that in non-CKD (10.6/1000 person-years). In contrast, stage 4 CKD manifested twofold higher incidence of newly developed diabetes (26.4/1000 person-years, $P=0.047$ ).

We further assessed the effects of candesartan and amlodipine on the development of diabetes in patients with $\mathrm{CKD}$. There was no difference in BMI between the candesartan group (26.0, 25.0 and $24.8 \mathrm{~kg} \mathrm{~m}^{-2}$ for stage $1+2,3$ and 4 , respectively) and amlodipine group (25.8, 25.0 and $24.6 \mathrm{~kg} \mathrm{~m}^{-2}$ for stage $1+2,3$ and 4 , respectively). In stage $1+2$ and stage $4 \mathrm{CKD}$, the incidence of new-onset diabetes was the same in candesartan-based and amlodipine-based regimens (Figure 7). In stage 3, however, the development of diabetes was significantly lower in the candesartan-treated group than in the amlodipine-treated group $(P=0.0498)$ despite higher percentages of the use of diuretics $(26.1$ vs. $14.8 \%, P<0.001)$ and $\beta$-blockers (23.8 vs. $18.6 \%, P=0.002)$ in the candesartan group. 
Renal Events in Patients with CKD
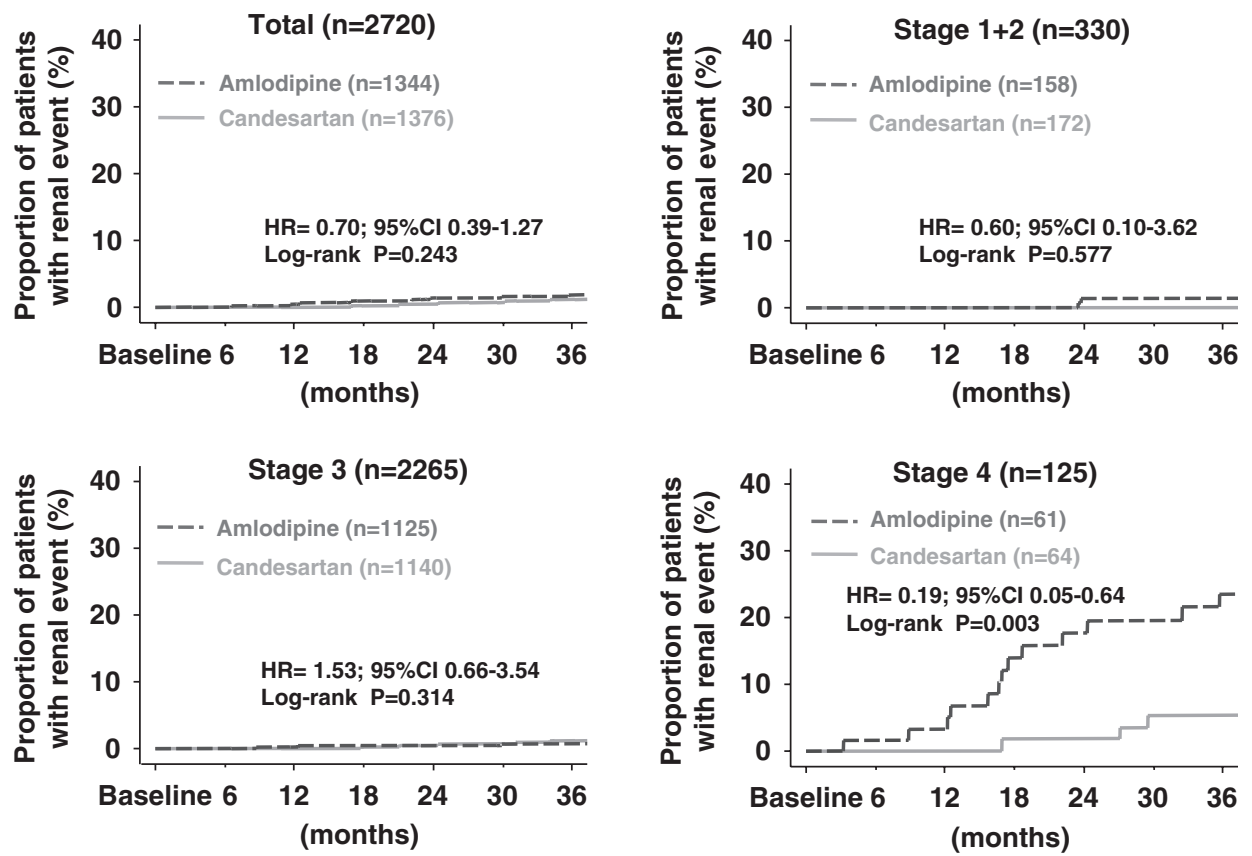

Figure 4 Kaplan-Meier curves of candesartan-based and amlodipine-based regimens for renal events in various CKD stages.
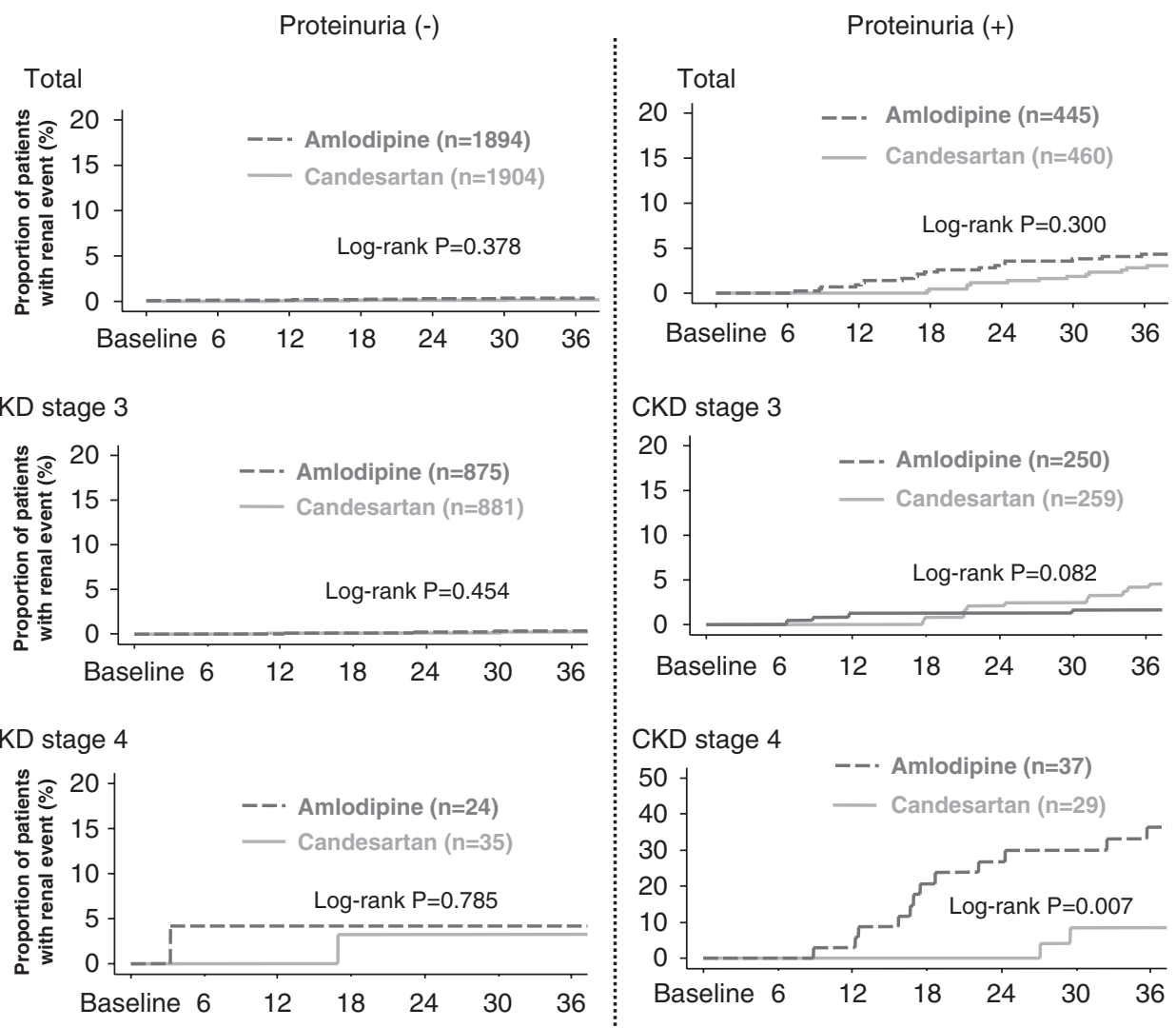

Figure 5 Kaplan-Meier curves of candesartan-based and amlodipine-based regimens for renal events in various CKD stages in the presence or absence of proteinuria. 

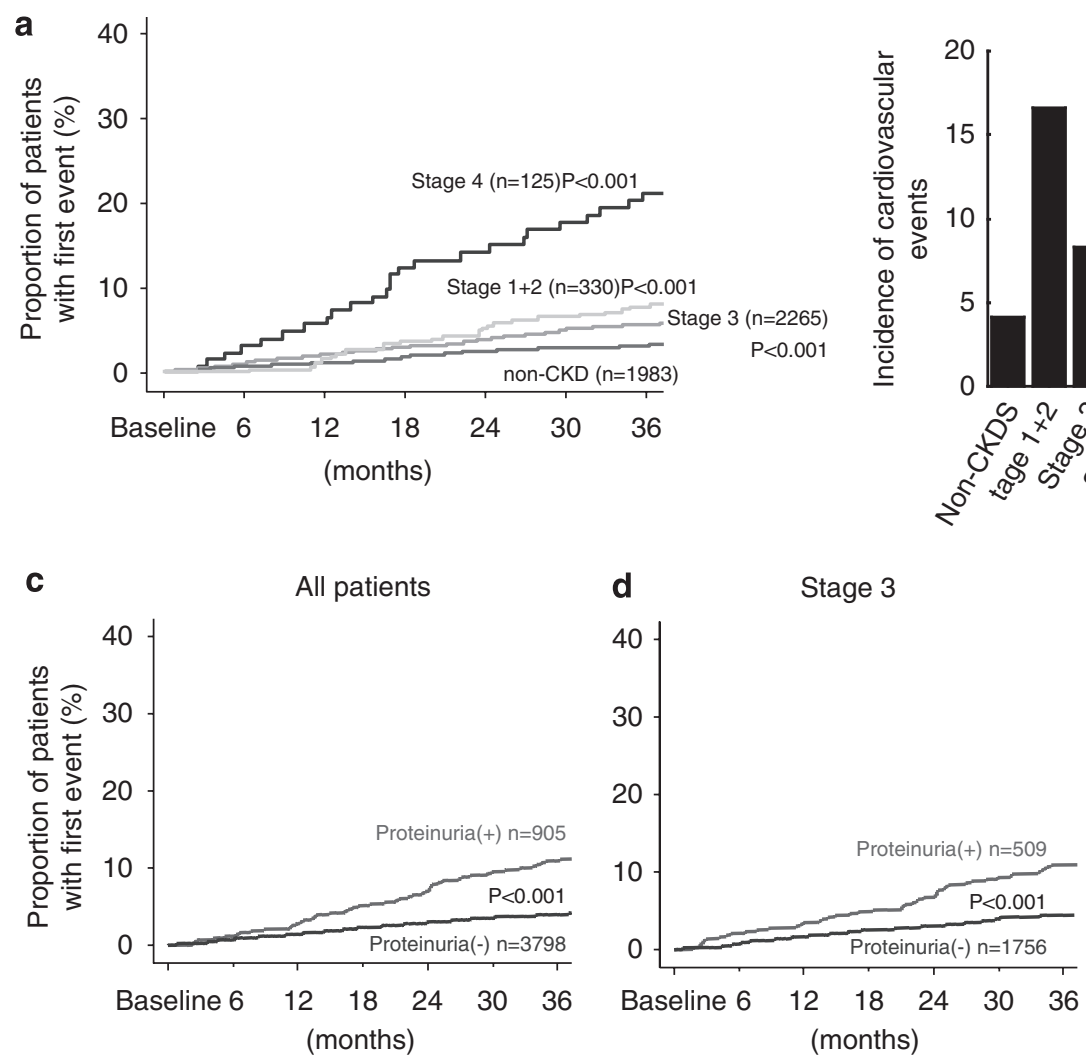

Figure 6 Effect of CKD stages and proteinuria on the incidence of cardiovascular events. (a) Kaplan-Meier curves of each CKD stage for composite cardiovascular end point. (b) Each category of cardiovascular events in various CKD stages is shown. (c-e) Effect of proteinuria on cardiovascular events in all patients (c), and in the patients with stage 3 (d) and stage 4 CKD (e).

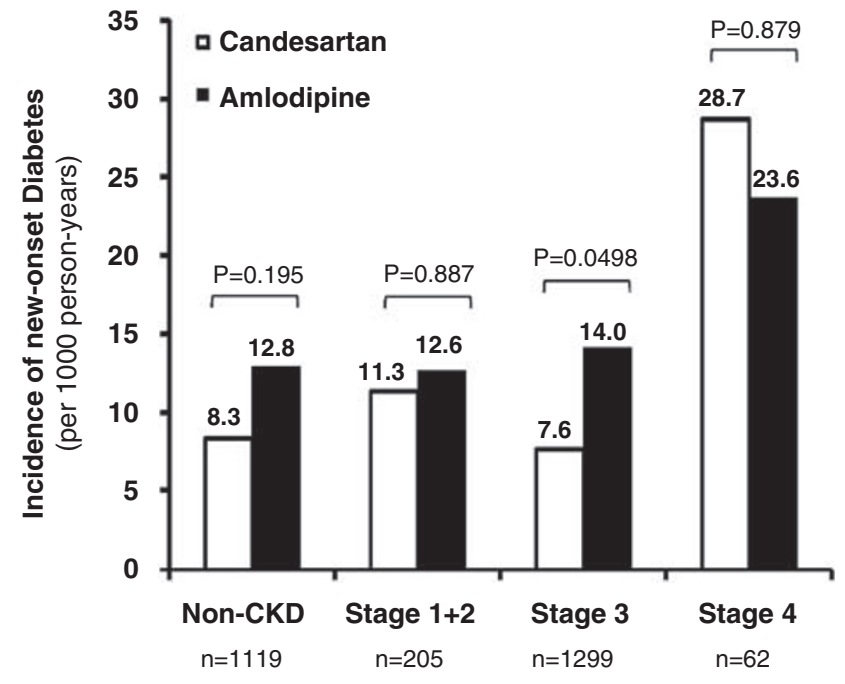

Figure 7 Effects of CKD on the incidence of new-onset diabetes in the candesartan-treated and amlodipine-treated group.

\section{DISCUSSION}

Since the recognition of CKD as a critical determinant of cardiovascular events, a growing body of evidence has been accumulated that impaired renal function is an important risk factor for the development of cardiovascular accidents. ${ }^{5,7,22}$ Among the therapeutic strate-

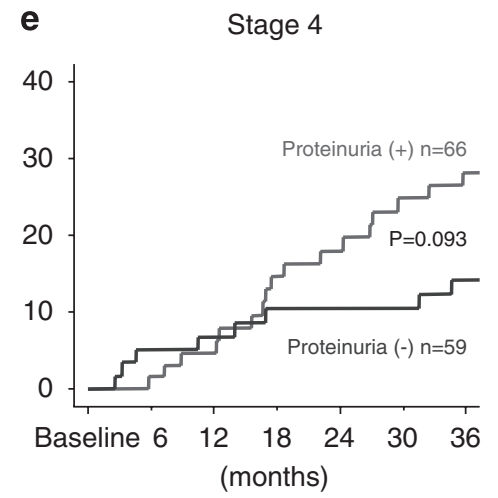

b Cerebrovascular Cardiac Renal

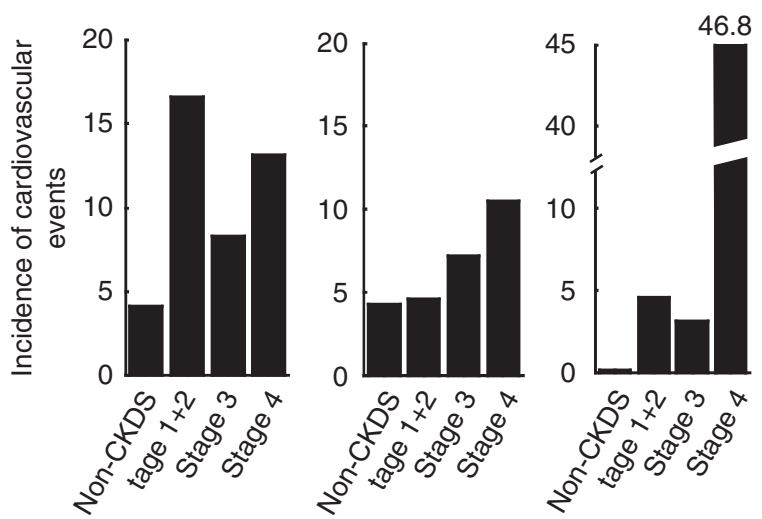

e gies, angiotensin blockade with the ACE inhibitor and the ARB constitutes an important tool for preventing the development of CKD and alleviating the cardiovascular accidents. ${ }^{10,23-26}$ In contrast, controversy attends the clinical relevancy on the effectiveness of CCB, with beneficial ${ }^{16,17}$ or detrimental effects on CKD observed by CCB. ${ }^{13,18}$ Furthermore, differences in ethnicity as well as lifestyle could affect the study outcome and may precipitate in different results from those obtained in earlier studies.

With the current sub-analysis focusing on the effect of CKD, the BP levels achieved with candesartan treatment were $1.2 \mathrm{~mm} \mathrm{Hg}$ higher than those with amlodipine. In this setting, we found no significant difference in the incidence of cardiovascular events between the candesartan regimen and amlodipine regimen in patients with CKD (Figure 2), a finding in accordance with our recent observations on the primary events for the CASE-J Study. ${ }^{20}$ When adjusted for the difference in systolic BP with Cox regression analysis, similar results were obtained. We further scrutinized the incidence rates of cardiovascular events based on the CKD stage, and found no difference in the event rate between the candesartan-based and the amlodipinebased regimen in stage $1+2$ or stage 3 (Figure 3 ). In stage $4 \mathrm{CKD}$, where the GFR is moderately to highly reduced (that is, GFR $<30 \mathrm{ml}$ per min per $1.73 \mathrm{~m}^{2}$ ), by contrast, the candesartan-based regimen conferred greater benefit than the amlodipine-based regimen for cardiovascular protection (HR: $0.45,95 \% \mathrm{CI}: 0.20-0.995, P=0.048$ ). Recently, Go et al. ${ }^{7}$ showed increased cardiovascular risks in patients with GFR less than $45 \mathrm{ml}$ per min per $1.73 \mathrm{~m}^{2}$. As both ARB and CCB are used commonly in the treatment of hypertension with $\mathrm{CKD}$, the 
current analysis demonstrating more superb action of candesartan than amlodipine would implicate clinical relevancy of candesartan as a therapeutic tool for CKD.

This study further evaluated the effects of candesartan and amlodipine on each cardiovascular end point in CKD. For cerebrovascular and cardiac events, these agents exerted similar action in any stage of CKD (Table 3). In contrast, candesartan more effectively alleviated the development of renal events than amlodipine in stage $4 \mathrm{CKD}$ (Figure 4); at 36 months, the event rate in candesartan-based regimen was $4.7 \%$, whereas the amlodipine-based regimen precipitated in $23.0 \%$ incidence of renal events. These findings suggest that renal events contribute largely to the development of cardiovascular events in stage $4 \mathrm{CKD}$. For stage $1+2$ and stage 3 , because the incidence of renal events in candesartan- and amlodipine-based regimens is small, it is appropriately conjectured that the difference between these incidence rates does not attain statistical significance. It is to be noted that earlier recommendations indicate the judicious use of renin/angiotensin blocking agents in CKD patients with serum creatinine level above $3 \mathrm{mg} \mathrm{dl}^{-1}$ because of acute deterioration in renal function. ${ }^{21}$ The subsequent study, however, has shown that benazepril effectively prevents the progression of $\mathrm{CKD}$ with baseline serum creatinine levels between 3.0 and $5.0 \mathrm{mg} \mathrm{dl}^{-1} .{ }^{27}$ In the current analysis, we actually observe a more favorable effect of candesartan on renal survival than that of amlodipine in stage 4 (Figure 4). A similar observation was documented in the IDNT Study, showing that irbesartan improved renal survival, whereas amlodipine failed to prevent the progression of $\mathrm{CKD} .{ }^{13}$ Collectively, it is reasonably concluded that ARBs, including candesartan, exert beneficial action on renal function even in moderately to severely advanced CKD, and the ability of candesartan to prevent the progression of CKD is greater than that of amlodipine.

A growing body of evidence has been accumulated that decreased GFR per se constitutes an important risk factor for development of cardiovascular accidents. ${ }^{6-8}$ Furthermore, even the presence of proteinuria is shown to entail the risks of subsequent cardiovascular damage, including cardiac hypertrophy, cerebrovascular accidents and coronary artery disease. ${ }^{6,22}$ In the current analysis, we found that all stages of CKD manifested higher risks for developing the events than the non-CKD group; the relative risk in the stage $1+2$ was elevated to 3.05 and a HR of 5.32 was observed in stage 4 CKD (Figure 6a). Furthermore, these increased risks are observed in the respective (that is, cerebrovascular and renal) cardiovascular events (Figure 6b). Finally, the presence of proteinuria is associated with higher risks of developing cardiovascular events. Much attention has been paid to the mechanisms for the CKD-mediated cardiovascular events. Several possible factors have been proposed as the mechanisms for cardiorenal syndrome, including anemia, reactive oxygen species and asymmetric dimethylarginine. ${ }^{28,29}$ Although the mechanism for the link between proteinuria and cardiovascular events remains undetermined, our current observations clearly indicate that proteinuria is a strong risk factor for cardiovascular events, particularly in the progression of $\mathrm{CKD}^{3,6,8}$ (Figures $6 \mathrm{c}$ and $\mathrm{d}$ ).

Evidence has accrued that CKD modifies the glucose metabolism. It is known that the progression of CKD impairs insulin degradation and subsequently ameliorates the control of diabetes. Alternatively, De Vinuesa et al. ${ }^{30}$ showed that insulin resistance developed in patients with stage 3-4 CKD. Kobayashi et al. ${ }^{31}$ also reported that insulin resistance was correlated linearly with the decline of renal function. This study has demonstrated that the new onset of diabetes is increased in stage $4 \mathrm{CKD}$, although the incidence is unaltered in the stage $1+2$ or stage 3 when compared with the non-CKD. This reason may be attributed to the use of antihypertensive agents. In our current study, in which the patients were given either ARB or CCB, the incidence of newly developed diabetes did not apparently increase in stages $1+2$ and 3 . In this regard, CCB with long-acting property has been reported to be neutral ${ }^{32}$ or slightly favorable to insulin sensitivity. ${ }^{33}$ On the other hand, ARB is established to offer beneficial action on insulin sensitivity. ${ }^{30,34}$ It is to noted that candesartan was more effective than amlodipine in preventing the development of diabetes in stage $3 \mathrm{CKD}$ (Figure 7). The salutary action of ARB is teleologically reflected by several encouraging large-scale clinical trials (for example, ALLHAT, $^{35}$ VALUE $^{36}$ ), showing the prevention of the development to diabetes by ARB. Our analysis, therefore, is consistent with the premise that ARB constitutes a first-line drug in the treatment of hypertension with CKD and also offers favorable action to prevent the development of diabetes.

In conclusion, both candesartan- and amlodipine-based regimens were able to control the BP of hypertensive patients with CKD. No differences were observed between the two agent groups in the incidence of cardiovascular events. In patients with severely impaired renal function, candesartan offered more favorable outcome than amlodipine in controlling the incidence of renal events. Finally, the ability of candesartan to prevent the new-onset diabetes was greater in moderately impaired CKD, which might contribute to the protection of cardiovascular events in CKD.

\section{CONFLICT OF INTEREST}

TS, TO, KN, TF and KF received honoraria for lectures from Takeda Pharmaceutical Co. and Pfizer Japan. The remaining authors report declare no conflicts of interest.

\section{ACKNOWLEDGEMENTS}

We thank all of the participants, physicians, medical staff and other contributors to the CASE-J Trial.: The CASE-J Trial was funded by EBM Research Center, Kyoto University of Graduate School of Medicine, with an unrestricted grant from Takeda Pharmaceutical Co. The Japanese Society of Hypertension supported the trial.

1 Manjunath G, Tighiouart H, Coresh J, Macleod B, Salem DN, Griffith JL, Levey AS, Sarnak MJ. Level of kidney function as a risk factor for cardiovascular outcome in the elderly. Kidney Int 2003; 63: 1121-1129.

2 Manjunath G, Tighiouart H, Ibrahim H, MacLeod B, Salem DN, Griffith JL, Coresh J, Levey AS, Sarnak MJ. Level of kidney function as a risk factor for atherosclerotic cardiovascular outcome in the community. J Am Coll Cardiol 2003; 41: 47-55.

3 Iseki K, Ikemiya Y, Iseki C, Takishita S. Proteinuria and the risk of developing end-stage renal disease. Kidney Int 2003; 63: 1468-1474.

4 Lysaght MJ. Maintenance dialysis population dynamics: current trends and long-term implications. J Am Soc Nephrol 2002; 13(Suppl 1): S37-S40.

5 Ninomiya T, Kiyohara Y, Kubo M, Tanizaki Y, Doi Y, Okubo K, Wakugawa Y, Hata J, Oishi Y, Shikata K, Yonemoto K, Hirakata H, lida M. Chronic kidney disease and cardiovascular disease in a general Japanese population: the Hisayama Study. Kidney Int 2005; 68: 228-236.

6 Irie F, Iso H, Sairenchi T, Fukasawa N, Yamagishi K, Ikehara S, Kanashiki M, Saito Y, Ota $\mathrm{H}$, Nose $\mathrm{T}$. The relationships of proteinuria, serum creatinine, glomerular filtration rate with cardiovascular disease mortality in Japanese general population. Kidney Int 2006; 69: 1264-1271.

7 Go AS, Chertow GM, Fan D, McCulloch CE, Hsu CY. Chronic kidney disease and the risks of death, cardiovascular events, and hospitalization. N Engl J Med 2004; 351: 1296-1305.

8 Tonelli M, Wiebe N, Culleton B, House A, Rabbat C, Fok M, McAlister F, Garg AX. Chronic kidney disease and mortality risk: a systematic review. J Am Soc Nephrol 2006; 17: 2034-2047.

9 The Japanese Society of Nephrology. Clinical Practical Guidebook for Diagnosis and Treatment of Chronic Kidney Disease. Nippon Jinzo Gakkai Shi 2007; 49: 755-870.

10 National Kidney Foundation. K/DOQI Clinical Practice Guidelines on Hypertension and Antihypertensive Agents in Chronic Kidney Disease. Am J Kidney Dis 2004; 43 : $1-290$. 
11 Imai E, Horio M, Iseki K, Yamagata K, Watanabe T, Hara S, Ura N, Kiyohara Y, Hirakata H, Moriyama T, Ando Y, Nitta K, Inaguma D, Narita I, Iso H, Wakai K, Yasuda Y, Tsukamoto Y, Ito S, Makino H, Hishida A, Matsuo S. Prevalence of chronic kidney disease (CKD) in the Japanese general population predicted by the MDRD equation modified by a Japanese coefficient. Clin Exp Nephrol 2007; 11: 156-163.

12 Dzau V. The cardiovascular continuum and renin-angiotensin-aldosterone system blockade. J Hypertens Supp/ 2005; 23: S9-S17.

13 Lewis EJ, Hunsicker LG, Clarke WR, Berl T, Pohl M, Lewis JB, Ritz E, Atkins RC, Rohde R, Raz I. Collaborative Study Group: Renoprotective effect of the angiotensin-receptor antagonist irbesartan in patients with nephropathy due to type 2 diabetes. N Eng/ J Med 2001; 345: 851-860.

14 Brenner BM, Cooper ME, de Zeeuw D, Keane WF, Mitch WE Parving HH, Remuzzi G, Snapinn SM, Zhang Z, Shahinfar S. RENAAL Study Investigators, Effects of losartan on renal and cardiovascular outcomes in patients with type 2 diabetes and nephropathy. $N$ Engl J Med 2001; 345: 861-869.

15 Pfeffer MA, Swedberg K, Granger CB, Held P, McMurray JJ, Michelson EL, Olofsson B, Ostergre J, Yusuf S, Pocock S, CHARM Investigators and Committee. Effects of candesartan on mortality and morbidity in patients with chronic heart failure: the CHARM-Overall programme. Lancet 2003; 362: 759-766.

16 de Leeuw PW, Ruilope LM, Palmer CR, Brown MJ, Castaigne A, Mancia G, Rosenthal T, Wagener G. Clinical significance of renal function in hypertensive patients at high risk: results from the INSIGHT trial. Arch Intern Med 2004; 164: 2459-2464.

17 Hayashi K, Kumagai $H$, Saruta T. Effect of efonidipine and ACE inhibitors on proteinuria in human hypertension with renal impairment. Am J Hypertens 2003; 16: 116-122.

18 Agodoa LY, Appel L, Bakris GL, Beck G, Bourgoignie J, Briggs JP, Charleston J, Cheek D, Cleveland W, Douglas JG, Douglas M, Dowie D, Faulkner M, Gabriel A, Gassman J, Greene T, Hall Y, Hebert L, Hiremath L, Jamerson K, Johnson CJ, Kopple J, Kusek J, Lash J, Lea J, Lewis JB, Lipkowitz M, Massry S, Middleton J, Miller III ER, Norris K, O'Connor D, Ojo A, Phillips RA, Pogue V, Rahman M, Randall OS, Rostand S, Schulman G, Smith W, Thornley-Brown D, Tisher CC, Toto RD, Wright Jr JT, Xu S, African American Study of Kidney Disease and Hypertension (AASK) Study Group. Effect of ramipril vs amlodipine on renal outcomes in hypertensive nephrosclerosis: a randomized controlled trial. JAMA 2001; 285: 2774-2776.

19 Fukui T, Rahman M, Hayashi K, Takeda K, Higaki J, Sato T, Fukushima M, Sakamoto J, Morita S, Ogihara T, Fukiyama K, Fujishima M, Saruta T, CASE-J Study Group. Candesartan Antihypertensive Survival Evaluation in Japan (CASE-J) trial of cardiovascular events in high-risk hypertensive patients: rationale, design, and methods. Hypertens Res 2003; 26: 979-990.

20 Ogihara T, Nakao K, Fukui T, Fukiyama K, Ueshima K, Oba K, Sato T, Saruta T, Candesartan Antihypertensive Survival Evaluation in Japan Trial Group. Effects of candesartan compared with amlodipine in hypertensive patients with high cardiovascular risks: candesartan antihypertensive survival evaluation in Japan trial. Hypertension 2008; 51: 393-398.

21 Japanese Society of Hypertension Guidelines Subcommittee for the Management of Hypertension. Guidelines for the management of hypertension for general practitioners. Hypertens Res 2001; 24: 613-634.

22 Sarnak MJ, Levey AS, Schoolwerth AC, Coresh J, Culleton B, Hamm LL, McCullough PA, Kasiske BL, Kelepouris E, Klag MJ, Parfrey P, Pfeffer M, Raij L, Spinosa DJ, Wilson PW. American Heart Association Councils on Kidney in Cardiovascular Disease, High Blood Pressure Research, Clinical Cardiology, and Epidemiology and Prevention:
Kidney Disease as a Risk Factor for Development of Cardiovascular Disease: A Statement From the American Heart Association Councils on Kidney in Cardiovascular Disease, High Blood Pressure Research, Clinical Cardiology, and Epidemiology and Prevention. Circulation 2003; 108: 2154-2169.

23 Chobanian AV, Bakris GL, Black HR, Cushman WC, Green LA, Izzo Jr JL, Jones DW, Materson BJ, Oparil S, Wright Jr JT, Roccella EJ. Seventh report of the Joint National Committee on Prevention, Detection, Evaluation, and Treatment of High Blood Pressure. Hypertension 2003; 42: 1206-1252.

24 The Task Force for the Management of Arterial Hypertension of the European Society of Hypertension (ESH) and of the European Society of Cardiology (ESC). 2007 Guidelines for the management of arterial hypertension. Eur Heart J 2007; 28: 1462-1536.

25 Japanese Society of Hypertension. Japanese Society of Hypertension guidelines for the management of hypertension (JSH2004). Hypertens Res 2006; 29 (Suppl): S1-S105.

26 National Kidney Foundation. K/DOQI clinical practice guidelines for chronic kidney disease: evaluation, classification, and stratification. Am J Kidney Dis 2002; 39: S1-S266.

27 Hou FF, Zhang X, Zhang GH, Xie D, Chen PY, Zhang WR, Jiang JP, Liang M, Wang GB, Liu ZR, Geng RW. Efficacy and safety of benazepril for advanced chronic renal insufficiency. N Engl J Med 2006; 354: 131-140.

28 Schiffrin EL, Lipman ML, Mann JF. Chronic kidney disease: effects on the cardiovascular system. Circulation 2007; 116: 85-97.

29 Zoccali C, Bode-Böger S, Mallamaci F, Benedetto F, Tripepi G, Malatino L, Cataliotti A, Bellanuova I, Fermo I, Frölich J, Böger R. Plasma concentration of asymmetrical dimethylarginine and mortality in patients with end-stage renal disease: a prospective study. Lancet 2001; 358: 2113-2117.

30 De Vinuesa SG, Goicoechea M, Kanter J, Puerta M, Cachofeiro V, Lahera V, GomezCampdera F, Luno J. Insulin resistance, inflammatory biomarkers, and adipokines in patients with chronic kidney disease: effects of angiotensin II blockade. J Am Soc Nephrol 2006; 17: S206-S212.

31 Kobayashi S, Maesato K, Moriya H, Ohtake T, Ikeda T. Insulin resistance in patients with chronic kidney disease. Am J Kidney Dis 2004; 45: 275-280.

32 De Courten M, Ferrari P, Schneider M, Bohlen L, Shaw S, Riesen W, Heynen G, Weidmann P. Lack of effect of long-term amlodipine on insulin sensitivity and plasma insulin in obese patients with essential hypertension. Eur J Clin Pharmacol 1993; 44: 457-462.

33 Harano Y, Kageyama A, Hirose J, Asakura Y, Yokota T, Ikebuchi M, Suzuki M, Omae T. Improvement of insulin sensitivity for glucose metabolism with the long-acting Ca-channel blocker amlodipine in essential hypertensive subjects. Metabolism 1995; 44: 315-319.

34 Koh KK, Quon MJ, Han SH, Chung WJ, Kim JA, Shin EK. Vascular and metabolic effects of candesartan: insights from therapeutic interventions. J Hypertens 2006; 24 (Suppl): S31-S38.

35 ALLHAT Collaborative Research Group. Major outcomes in high-risk hypertensive patients randomized to angiotensin-converting enzyme inhibitor or calcium channel blocker vs. diuretic. JAMA 2002; 288: 2981-2997.

36 Julius S, Kjeldsen SE, Weber M, Brunner HR, Ekman S, Hansson L, Hua T, Laragh J, Mclnnes GT, Mitchell L, Plat F, Schork A, Smith B, Zanchetti A, VALUE Trial Group. Outcomes in hypertensive patients at high cardiovascular risk treated with regimens based on valsartan or amlodipine: the VALUE randomised trial. Lancet 2004; 363: 2022-2031. 